\title{
Study of maternal and perinatal outcome of caesarean delivery in late first stage and second stage of labour
}

\author{
Shweta Bhatia, Vijaya M. Revankar*
}

Department of Obstetrics and Gynecology, KMC Mangalore, Karnataka, India

Received: 21 January 2021

Revised: 02 March 2021

Accepted: 03 March 2021

\section{*Correspondence:}

Dr. Vijaya M. Revankar,

E-mail: manohar.revankar@gmail.com

Copyright: (C) the author(s), publisher and licensee Medip Academy. This is an open-access article distributed under the terms of the Creative Commons Attribution Non-Commercial License, which permits unrestricted non-commercial use, distribution, and reproduction in any medium, provided the original work is properly cited.

\section{ABSTRACT}

Background: Second-stage caesarean sections are known to be associated with increased maternal and perinatal complications as compared to late first stage caesarean sections. The objective of the study was to evaluate the maternal and perinatal outcome of caesarean deliveries in the late first stage and second stage of labour.

Methods: The prospective observational study of caesarean deliveries done in the late first stage $(\sim 8 \mathrm{~cm}$ of cervical dilatation) and second stage of labour was conducted at Lady Goshen Hospital, Mangalore and Kasturba Medical College Attavar, Mangalore from August 2018 to June 2020. Comparison of maternal and perinatal outcomes were assessed in late first stage and second stages of caesarean delivery.

Results: In the present study intraoperative complications such as extensions of uterine incisions, atonic PPH and bladder base injury and post-operative complications like need for blood transfusion, febrile morbidity and prolonged catheterisation were found more in second stage of labour. Perinatal complications such as hyperbilirubinemia and respiratory distress were found to be more in second stage of labour.

Conclusions: As caesarean deliveries are increasing, it is better to make an institutional protocol regarding duration of second stage of labour, use of instrumental delivery to guide us about timely intervention (operative vaginal/caesarean) in advanced labour, thereby aiming to reduce the maternal and perinatal complications.

Keywords: Caesarean, Labour, Second stage of labour

\section{INTRODUCTION}

Caesarean "delivery is the term commonly used to describe the delivery of a fetus through an abdominal and uterine incision". It is the most commonly performed major abdominal operation in women in both industrialized and low income countries. Caesarean“ delivery has played a major role in lowering both the maternal and perinatal morbidity and mortality during the past century. ${ }^{1}$

The overall rate of caesarean section delivery in 2015-16 is around $17.2 \%$ in India, increased from $8.5 \%$ in 2005 $06 .^{2}$ One fourth of the primary caesarean section is reported to be performed in the second stage of labour and is more complicated compared to the ones performed in the first stage. ${ }^{3}$

Second stage of labour begins when cervical dilatation is complete and ends with the fetal delivery. Second stage interventions are the methods to facilitate delivery of fetus in the form of assisted vaginal delivery or by instrumental delivery. ${ }^{4}$

The morbidity related to a prolonged second stage is directly $\mathrm{k}$ correlated with the incidence of extension of uterine angles and $\mathrm{p}$ prolonged surgical time, bladder injury and increased incidence of postpartum hemorrhage and hospitalustay. ${ }^{5}$ Neonatal mortality and morbidity is mainly due to hypoxia and fetal trauma. 
Second-stage Caesarean sections are known to be associated with increased maternal and perinatal complications compared to late first stage caesarean sections.

The objectives of this study was to evaluate the maternal and perinatal outcome of caesarean deliveries done in the late first stage and second stage of labour.

\section{METHODS}

A prospective study was done at Lady Goschen Hospital Mangaluru and Kasturba Medical College, Attavar, Mangaluru over a period of 18 months from August 2018 to June 2020 . All cases in the late first stage $(\sim 8 \mathrm{~cm}$ of cervical dilatation) and second stage caesarean deliveries were included in study. A prestructured questionnaire was prepared and data was collected accordingly.

All term pregnant women admitted in our hospital with single live pregnancy who underwent caesarean delivery in late first stage and second stage of labour were included. Late first stage included patients with more than $8 \mathrm{~cm}$ cervical dilatation.

Indications for the caesarean delivery, technique of delivery of fetal head, attempt of instrumental delivery were recorded.

Intraoperative complications like atonic $\mathrm{PPH}$, extensions of uterine incisions, injury to the bladder, were recorded.

Postoperative complications like febrile illness, need for blood transfusions, wound infection, Urinary tract infections were noted.

Neonatal outcomes were assessed by need for NICU admission, any neonatal complications diagnosed and treated were noted.

\section{Inclusion criteria}

Singleton pregnancy irrespective of parity and Period of gestation of $>37$ weeks.

\section{Exclusion criteria}

Multiple pregnancy, Preterm deliveries, Malpresentations and Pregnancy with medical complications.

Study parameters included, maternal factors such as indication for LSCS, attempt of instrumental delivery, intraoperative and postoperative complications. Perinatal complications such as, need for NICU admissions, hyperbilirubinemia requiring phototherapy and respiratory distress.
Analysis was done using descriptive statistics. A statistical package SPSS Version 17.0 was used for analysis.

\section{RESULTS}

A prospective study of maternal and perinatal outcome of caesarean section done in late first stage and second stage of labour was studied over a period of 18 months (August 2018-June 2020). A sample of 217 cases were studied and results were observed accordingly.

Majority of the women included in the study were the ones who were operated when they were in the second stage of labour, as depicted in the Table 1.

Table 1: Total number of cases $(n=217)$.

\begin{tabular}{|c|c|}
\hline $\begin{array}{l}\text { Second stage of labour (fully dilated } \\
\text { cervix) }\end{array}$ & 154 \\
\hline $\begin{array}{l}\text { Late first stage ( } 8 \mathrm{~cm} \text { of cervical } \\
\text { dilatation) }\end{array}$ & 63 \\
\hline
\end{tabular}

Among both the groups i.e. women who underwent caesarean section when they were in the late first stage of labour (>8 cm cervical dilatation) and in the second stage of labour majority of the cases were Primigravida.

Amongst the women operated in the second stage of labour, most common indication for caesarean delivery was Arrest of Descent contributing to $77.9 \%$ of the total cases.

While non reassuring fetal heart status was the most common indication for caesarean section in the late first stage of labour accounting for $69.8 \%$ of the cases. The following is depicted in Table 2 and Figure 1, 2.

Table 2: Indications for LSCS.

\begin{tabular}{|c|c|c|c|}
\hline \multicolumn{2}{|c|}{ Stage of labour } & $\begin{array}{l}\text { Number } \\
(n=217)\end{array}$ & Percent \\
\hline \multirow{4}{*}{$\begin{array}{l}\text { Second } \\
\text { stage of } \\
\text { labour } \\
\text { (fully } \\
\text { dilated } \\
\text { cervix) }\end{array}$} & $\begin{array}{l}\text { Arrest of } \\
\text { descent }\end{array}$ & 120 & 77.9 \\
\hline & $\begin{array}{l}\text { Deep } \\
\text { transverse } \\
\text { arrest }\end{array}$ & 28 & 18.2 \\
\hline & $\begin{array}{l}\text { Failed } \\
\text { forceps }\end{array}$ & 6 & 3.9 \\
\hline & Total & 154 & 100.0 \\
\hline \multirow{4}{*}{$\begin{array}{l}\text { Late first } \\
\text { stage of } \\
\text { labour ( } 8 \\
\text { cm of } \\
\text { cervical } \\
\text { dilatation) }\end{array}$} & Breech & 3 & 4.8 \\
\hline & NRFHS & 44 & 69.8 \\
\hline & $\begin{array}{l}\text { Protracted } \\
\text { dilatation }\end{array}$ & 16 & 25.3 \\
\hline & Total & 63 & 100.0 \\
\hline
\end{tabular}




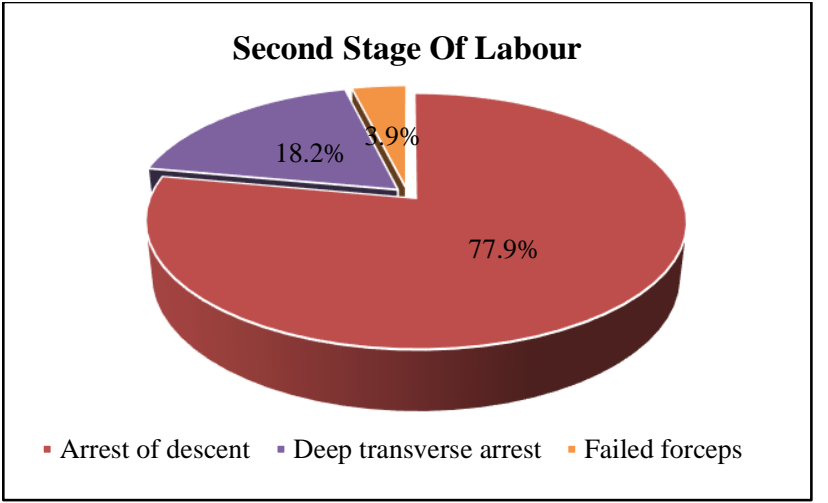

Figure 1: Depicting the indications for caesarean section: in second stage of labour.

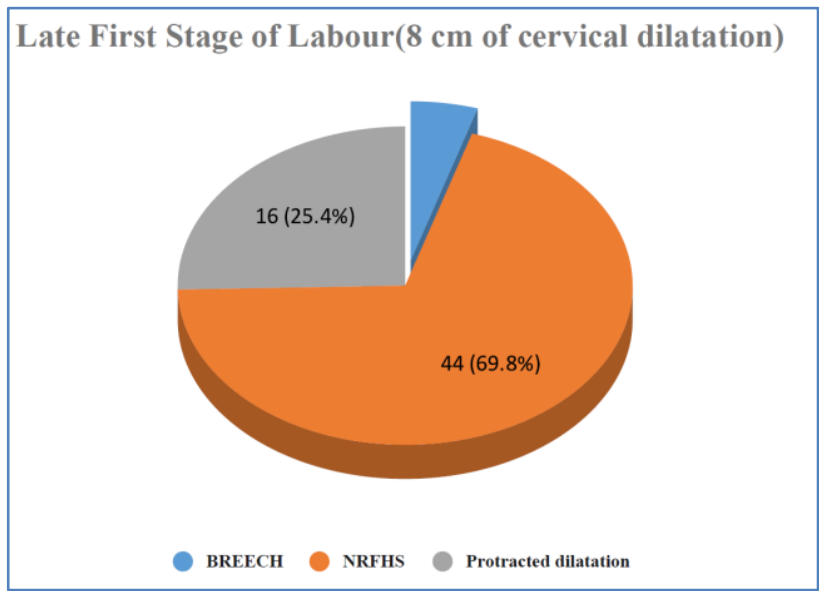

Figure 2: Depicting the indications for caesarean section: in late first stage of labour.

Intraoperative complications observed among women operated in the second stage of labour observed was extension of uterine incision accounting to $18.1 \%$ of the total complications, as shown in the Table 3 and Figure 3.

Table 3: Intra-operative complications.

\begin{tabular}{|c|c|c|c|}
\hline \multicolumn{2}{|c|}{ Stage of labour } & \multirow{2}{*}{$\begin{array}{l}\text { Number } \\
n=217 \\
21\end{array}$} & \multirow{2}{*}{$\begin{array}{l}\% \\
13.7\end{array}$} \\
\hline Second & Atonic PPH & & \\
\hline stage of & Bladder base injury & 2 & 1.3 \\
\hline $\begin{array}{l}\text { labour } \\
\text { (fully }\end{array}$ & $\begin{array}{l}\text { Extension of uterine } \\
\text { incision }\end{array}$ & 28 & 18.1 \\
\hline $\begin{array}{l}\text { d1lated } \\
\text { cervix) }\end{array}$ & $\begin{array}{l}\text { Peripartum } \\
\text { hysterectomy }\end{array}$ & 1 & 0.6 \\
\hline \multirow{3}{*}{$\begin{array}{l}\text { Late first } \\
\text { stage of } \\
\text { labour } \\
(8 \mathrm{~cm} \text { of } \\
\text { cervical } \\
\text { dilatation } \\
\text { ) }\end{array}$} & Total & 52 & 33.7 \\
\hline & $\begin{array}{l}\text { Atonic PPH } \\
\text { Uterine angle } \\
\text { extension }\end{array}$ & $\begin{array}{l}6 \\
1\end{array}$ & $\begin{array}{l}9.5 \\
1.6\end{array}$ \\
\hline & Total & 7 & 11.1 \\
\hline
\end{tabular}

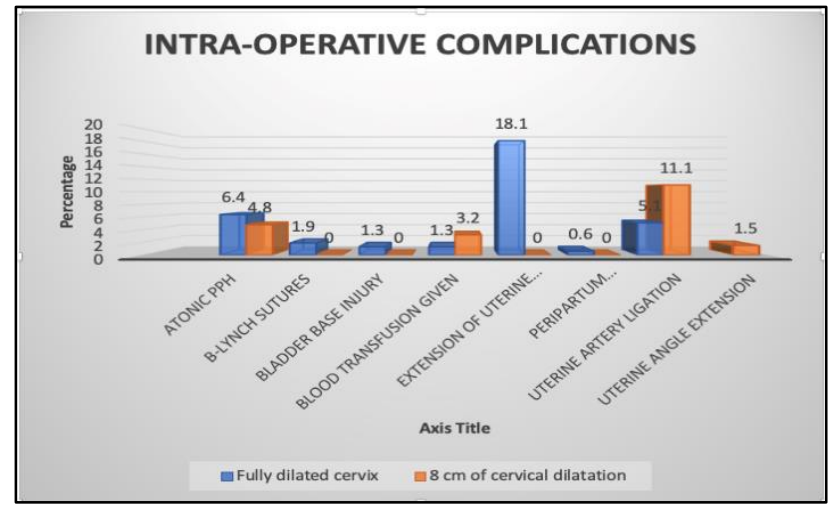

Figure 3: Intra-operative complications.

Table 4: Post operative complications.

\begin{tabular}{|c|c|c|c|}
\hline \multicolumn{2}{|c|}{ Stage of labour } & $\begin{array}{l}\text { Numb } \\
\text { er } \\
n=217\end{array}$ & $\%$ \\
\hline \multirow{9}{*}{$\begin{array}{l}\text { Second } \\
\text { stage of } \\
\text { labour } \\
\text { (fully } \\
\text { dilated } \\
\text { cervix) }\end{array}$} & $\begin{array}{l}\text { Blood transfusion } \\
\text { given }\end{array}$ & & \\
\hline & Febrile morbidity & 14 & 9.1 \\
\hline & Hematuria & 12 & 7.8 \\
\hline & $\begin{array}{l}\text { Prolonged } \\
\text { catheterisation }\end{array}$ & 2 & 1.3 \\
\hline & Secondary suturing & 8 & 5.2 \\
\hline & Urinary retension & 1 & 0.6 \\
\hline & $\begin{array}{l}\text { Urinary tract } \\
\text { infection }\end{array}$ & 1 & 0.6 \\
\hline & Wound infection & 7 & 4.6 \\
\hline & $\begin{array}{l}\text { Total } \\
\text { complications }\end{array}$ & 3 & 1.9 \\
\hline \multirow{7}{*}{$\begin{array}{l}\text { Late first } \\
\text { stage of } \\
\text { labour ( } 8 \\
\text { cm of } \\
\text { cervical } \\
\text { dilatation) }\end{array}$} & $\begin{array}{l}\text { Blood transfusion } \\
\text { given }\end{array}$ & & \\
\hline & Febrile morbidity & 5 & 7.9 \\
\hline & Secondary suturing & 6 & 9.5 \\
\hline & $\begin{array}{l}\text { Urinary tract } \\
\text { infection }\end{array}$ & 1 & 1.6 \\
\hline & $\begin{array}{l}\text { Wound infection } \\
\text { noted }\end{array}$ & 1 & 1.6 \\
\hline & $\begin{array}{l}\text { Total } \\
\text { complications }\end{array}$ & 2 & 3.2 \\
\hline & & 15 & 23.8 \\
\hline
\end{tabular}

Postoperative complications were studied in both the groups. The most common post-operative complication in the cases operated when they were in the second stage of labour was need for blood transfusion seen in $9.1 \%$ of cases, while febrile morbidity accounted for $9.5 \%$ of the total postoperative complications among the women who were operated when they were in the late first stage of labour as shown in the Table 4 and Figure 4.

Out of 217 study subjects patients who underwent caesarean section in the second stage of labour, perinatal complications such as hyperbilirubinemia was observed in 7.8 percent of cases followed by respiratory distress 
observed in $5.8 \%$ of the cases, stillbirth was observed in 1 case, accounting to 0.6 percent of the perinatal complications. Subjects who were operated in the late first stage of labour i.e. at $8 \mathrm{~cm}$ of cervical dilatation, perinatal complication such as hyperbilirubinemia was observed in $7.9 \%$ of the cases, followed by respiratory distress observed in $4.8 \%$ of the cases. The following is depicted in the Table 5 and Figure 5.

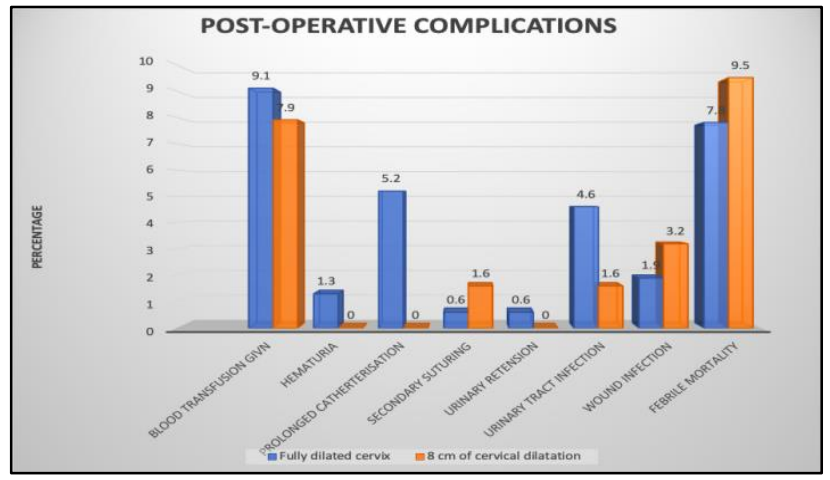

Figure 4: Post-operative complications.

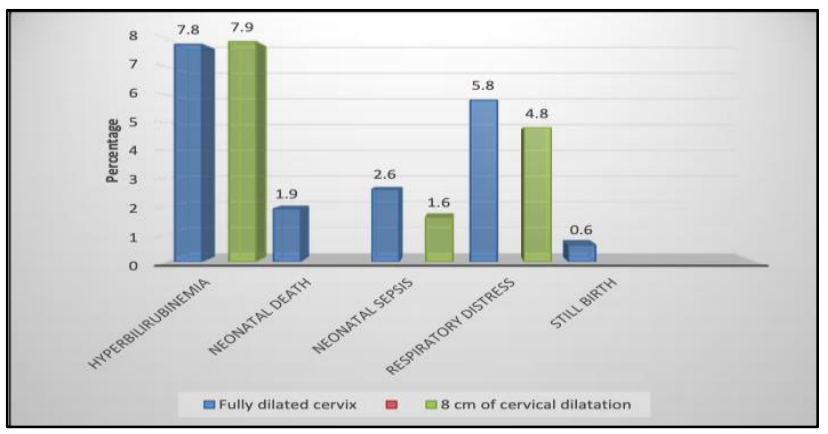

Figure 5: Perinatal complications.

Table 5: Perinatal complications.

\begin{tabular}{|c|c|c|c|}
\hline \multicolumn{2}{|c|}{ Stage of labour } & $\begin{array}{l}\text { Number } \\
\mathrm{n}=\mathbf{2 1 7}\end{array}$ & $(\%)$ \\
\hline \multirow{6}{*}{$\begin{array}{l}\text { Second } \\
\text { stage of } \\
\text { labour } \\
\text { (fully } \\
\text { dilated } \\
\text { cervix) }\end{array}$} & $\begin{array}{l}\text { Hyperbilirubine } \\
\text { mia }\end{array}$ & 12 & 7.8 \\
\hline & Neonatal death & 3 & 1.9 \\
\hline & Neonatal sepsis & 4 & 2.6 \\
\hline & $\begin{array}{l}\text { Respiratory } \\
\text { distress }\end{array}$ & 9 & 5.8 \\
\hline & Stillbirth & 1 & 0.6 \\
\hline & $\begin{array}{l}\text { Total } \\
\text { complications }\end{array}$ & 29 & 18.7 \\
\hline \multirow{4}{*}{$\begin{array}{l}\text { Late first } \\
\text { stage of } \\
\text { labour ( } 8 \\
\text { cm of } \\
\text { cervical } \\
\text { dilatation } \\
\text { ) }\end{array}$} & $\begin{array}{l}\text { Hyperbilirubine } \\
\text { mia }\end{array}$ & 5 & 7.9 \\
\hline & Neonatal sepsis & 1 & 1.6 \\
\hline & $\begin{array}{l}\text { Respiratory } \\
\text { distress }\end{array}$ & 3 & 4.8 \\
\hline & $\begin{array}{l}\text { Total } \\
\text { complications }\end{array}$ & 9 & 14.3 \\
\hline
\end{tabular}

\section{DISCUSSION}

Caesarean section in the second stage of labor is a technically difficult operation with distortion of maternal pelvic anatomy and deeply impacted fetal head in the maternal pelvis.

The present study is a time bound observational study, approximately 217 cases were studied, out of which 154 cases were in second stage of labour and 63 cases were in the late first stage of labour, as determined by per vaginal examination.

Which means out of 217 caesarean sections conducted, 154 sections were performed in the second stage of labour which contributes to 71 percent of the total deliveries and rest 29 percent contributed by the late first stage of the labour.

In the present study, most common indication for caesarean section, in the second stage of labour was arrest of descent which was comparable to the studies done by $\mathrm{T}$ Shobha et all i.e. $56.2 \%$ and Anusha $\mathrm{S} \mathrm{R}$ et al i.e. $76.7 \%$, while in the late first stage of labour was non reassuring fetal heart status accounting for $69.8 \%$ which was comparable to the studies done by Anusha S R et al $71.4 \%{ }^{6}$

However, According to the study done by T Shobha et all protracted dilatation was the most common indication for caesarean sections in late first stage of labour, accounting for $65 \%$ which stands in contrast to our study.

\section{Intra-operative complications}

A study conducted by Kamal D Goswami et al 2019 shows, most common intra-operative complication was extensions of uterine incision noted in $16 \%$ of the cases, rest are atonic PPH noted in $8 \%$, bladder injury in $6 \%$ and peripartum hysterectomy in $4 \%$ of the cases. ${ }^{7}$

In the study of intra-operative and postoperative maternal complications of caesarean section done by Dr Fasubaa $\mathrm{Ob}$ et all 2015, the overall maternal intra-operative complication rate was $14.8 \% .^{8}$ The most common complications was extension of uterine incisions i.e. 10 . $1 \%$ and blood loss $\geq 1000 \mathrm{ml}$, bladder injury noted in $3 \%$ of the cases and peripartum hysterectomy done in $2 \%$ of the cases. In the present study, Out of 217 cases of Csections, most common intra operative complications were Extension of uterine incision accounting for $13.36 \%$ cases, and Atonic postpartum Haemorrhage accounting to $12.44 \%$ of the total complications.

In the late first stage group, atonic post-partum haemorrhage is the major complication, seen in $9.5 \%$ of the total cases.

In the second stage group extension of uterine incision seen in $18.1 \%$ of cases, atonic post- partum haemorrhage 
seen in $13.7 \%$ of total cases, bladder base injury in $1.3 \%$ of the cases and peripartum hysterectomy in 1 case, accounting to $0.6 \%$.

\section{Post-operative complications}

In a study of fetomaternal outcome in cesarean sections done in second stage of labour conducted by Jayaram $\mathrm{J}$ et al in the year 2014, maternal morbidity was observed in the form of blood transfusions in $11 \%$ of cases, febrile morbidity in $15.38 \%$ of cases, need for prolonged catheterisation in $7.5 \%$ of cases and wound sepsis in $3.84 \%$ of the cases. ${ }^{9}$

In the study conducted by Goswami KD et al, 2019, most common postoperative complications were febrile morbidity observed in $14 \%$ of the total cases, followed by need for blood transfusions in $12 \%$ cases, wound infections observed in $8 \%$ and the need for prolonged catheterisation in $10 \%$ of cases. ${ }^{7}$

In the present study of late first stage group Febrile morbidity is the most common complication, accounting for $9.5 \%$ of the total complications, blood transfusions given in $7.9 \%$ of cases secondary to atonic $\mathrm{PPH}$, is the second most common complication, other complications are wound infection, secondary infection, urinary tract infection.

In the fully dilated patients most common complication was blood transfusion in $9.1 \%$ of the cases followed by febrile morbidity observed in $7.8 \%$ of cases and prolonged catheterization in $5.2 \%$ of cases, urinary tract infection in $4.6 \%$ of the cases rest were haematuria, urinary retention, wound infection and secondary suturing.

Overall, Febrile morbidity is the most common complication in both study groups.

\section{Perinatal complications}

In a study conducted by Jayaram $\mathrm{J}$ et al, more number of NICU admissions were reported among the neonates borne to the mothers by LSCS in second stage of labour i.e in $14.4 \%$ of the cases, as compared to those done in the late first stage of labour which was comparable to the present study where NICU care was required in $14.8 \%$ of the newborns. ${ }^{9}$

Perinatal complications included neonatal death, septicemia, respiratory distress and hyperbilirubinemia which were found to be associated more with the second stage caesarean sections which was comparable to the studies done by Jayaram $\mathrm{J}$ et al.

\section{Limitations}

The limitations in this study were seen with regard to the sample size and also the study did not study the effect of second stage caesarean sections on less common but serious outcomes such as peripartum hysterectomy, maternal death and perinatal death in detail.

\section{CONCLUSION}

Caesarean delivery during the second stage of labour is quite difficult due to deeply impacted fetal head, difficulty in delineating the bladder, difficulty in identification of limits of lower uterine segment and decreased amniotic fluid. The increased incidence of haemorrhage was due to intraoperative tear, extensions and uterine atony.

As caesarean deliveries are increasing day by day, it is better to make an institutional protocol regarding duration of second stage of labour, use of instrumental delivery to guide us regarding the timely intervention (operative vaginal/caesarean) in advanced labour by a skilled obstetrician, thereby aiming to reduce the maternal and perinatal complications.

\section{ACKNOWLEDGMENTS}

Authors would like to thank guide Dr Vijaya M Revankar, Professor, Department of Obstetrics and Gynaecology, Kasturba Medical College, Mangalore for all the valuable advice and guidance without which completion of article would not have been possible. Author thanks all the patients enrolled in this study for their constant support in the course of this study.

Funding: No funding sources

Conflict of interest: None declared

Ethical approval: The study was approved by the Institutional Ethics Committee Kasturba Medical College, Mangalore. Protocol Number: IEC KMC MLR 08-18/182

\section{REFERENCES}

1. Ronald G, Karlan S, Beth Y. Cesarean delivery. 10th ed. Danforth's Obstetr Gynecol, Lippincott Publications. 2008;27:490-1.

2. Desai G, Anand A, Modi D, Shah S, Shah K, Shah $\mathrm{A}$, et al. Rates, indications, and outcomes of caesarean section deliveries: A comparison of tribal and non-tribal women in Gujarat, India. PLoS One. 2017; 12(12):e0189260.

3. Gifford DS, Morton SC, Fiske M, Keesey J, Keeler E, Kahn KL. Lack of progress in labor as a reason for cesarean. Obstet Gynecol. 2000;95(4):589-95.

4. Bugg GJ, Siddiqui F, Thornton JG. Oxytocin versus no treatment or delayed treatment for slow progress in the first stage of spontaneous labour. Cochrane Database Syst Rev. 2011;(7):CD007123.

5. Asıcıoglu O, Güngördük K, Yildirim G, Asıcıoglu BB, Güngördük OÇ, Ark C, Günay T, Yenigül N. Second-stage vs first-stage caesarean delivery: 
comparison of maternal and perinatal outcomes. J Obstet Gynaecol. 2014;34(7):598-604.

6. Anusha SR, Deepak AV, Jacob KJ. Maternal and neonatal outcome in second stage cesarean section versus first stage: a comparative study. International Journal of Reproduction, Contraception, Obstetr and Gynecol. 2018;7(11):4640-5.

7. Goswami KD, Parmar MM, Kunjadiya AN. Study of fetomaternal outcome in second stage caesarean section. International Journal of Reproduction, Contraception, Obstetrics and Gynecol. 2019;8(6):2169-71.

8. Fasubaa OB, Ezechi OC, Orji EO, Ogunniyi SO, Akindele ST, Loto OM, et al. Delivery of the impacted head of the fetus at caesarean section after prolonged obstructed labour: a randomised comparative study of two methods. J Obstet Gynaecol. 2002;22(4):375-8.

9. Jayaram J, Mahendra G, Vijayalakshmi S. Fetomaternal Outcome in Cesarean Sections Done in Second Stage of Labor. Indian Journal of Obstetrics and Gynecology Research. 2016;3(51).

Cite this article as: Bhatia S, Revankar VM. Study of maternal and perinatal outcome of caesarean delivery in late first stage and second stage of labour. Int J Reprod Contracept Obstet Gynecol 2021;10:1503-8. 